\title{
Vozes em diáspora: como crianças imigrantes contam suas histórias
}

\author{
Voices in diaspora: how immigrant children tell their stories
}

Luciana Hartmann

RMA

Dossier
Bolsista de Produtividade em Pesquisa do CNPq. Departamento de Artes Cênicas, PPGCEN, Universidade de Brasília, Brasil. email: luhartm71@gmail.com

\section{Resumo}

Baseado em pesquisa etnográfica realizada durante 12 meses, em classes especiais de acolhimento para crianças não-francófonas (EPE2A) de duas escolas públicas de ensino fundamental na cidade de Paris - França, este artigo busca compreender como as experiências destas crianças são organizadas através de performances narrativas. Embora estas crianças sejam provenientes de países, classes sociais, grupos étnicos e religiões radicalmente distintos, elas convivem cotidianamente nesta classe na qual a única forma de comunicação é a língua francesa. Desta maneira, contar e compartilhar histórias torna-se um desafio para estes estudantes. Este artigo analisa como e o que contam estas crianças imigrantes nesta situação de intenso contato multicultural.

Palavras-chave: performance narrativa, crianças, narrativas orais, imigrantes, escola.

\begin{abstract}
Based on ethnographic research conducted during 12 months at two elementary public schools in Paris, focusing a special class to France newcomers (EPE2A), this article intends to know how the experiences of these children are being organized through oral and written narratives. Although these children come from different countries and social classes, belonging to distinct ethnic groups and with radically different religious, they live daily in this classroom where the unique form of oral communication is the French language (still unfamiliar for the majority). In that manner, tell and share stories becomes a challenge to each student. This paper analyzes how and what immigrant children tell in such situation of intense multicultural contact.
\end{abstract}

Keywords: narrative performance, children, oral narratives, immigrants, school.

Vou tratar aqui de um assunto que tem ganhado notabilidade recentemente na mídia internacional: o dilema do enorme contingente de refugiados que estão imigrando para a Europa. Na verdade, vou tratar de uma parcela específica dessa população que, à despeito da comoção global causada pela exposição das trágicas imagens de seus pequenos corpos naufragados em praias do Mediterrâneo, ainda vêm recebendo pouca atenção: as crianças ${ }^{1}$.

Talvez por ser mãe de duas crianças, talvez por pesquisar narrativas orais a cerca de 20 anos, quando tive oportunidade de eleger um tema para pesquisar em meu pós-doutorado², não hesitei, seriam as performances

\footnotetext{
${ }^{1}$ Na mesma semana em que as fotos de um menino sírio Aylan Kurdi, de 3 anos, que morrera afogado ao tentar a travessia do Mediterrâneo com a família, correram o mundo, me deparei com a seguinte frase de Carlos Skliar, escrita em artigo de 2003: "O outro multicultural naufraga como imagem entre o ser-diverso e o ser-diferente." A literalidade do naufrágio desse pequeno "outro multicultural" me arrebatou.

${ }^{2}$ Minha formação interdisciplinar em Artes Cênicas e em Antropologia, encontrou na polissemia da noção de performance um campo fértil a ser explorado, por este motivo a opção pela abordagem das "performances narrativas".
}

narrativas de crianças em situação de contato intercultural - no caso, crianças imigrantes recém-chegadas na França3. Intrigada pelos encontros intersubjetivos que se dão nesse espaço institucional que recebeu o monopólio da "educação", decidi realizar a pesquisa em escolas.

Antes de iniciar a desafiante e incerta pesquisa em instituições francesas, optei por realizar uma pesquisa experimental durante 3 meses em uma escola pública da periferia de Brasília, capital do Brasil, onde moro. Saí de lá com um rico material narrativo, com uma noção bem mais clara do funcionamento da instituição, em todas as suas esferas, mas o mais importante foi a experiência que adquiri na relação com as crianças e com sua produção expressivo-narrativa (Hartmann 2015). Essa experiência foi fundamental para o desenvolvimento do trabalho que realizei em duas escolas públicas da cidade de Paris, entre 2014 e 2015, em turmas das UPE2A (Unité Pédagogique pour Élèves Allophones Arrivants), classes especiais que acolhem crianças entre 06 e 12 anos. A denominação UPE2A é recente e como estas classes continuam a ser chamadas informalmente, por alunos e

${ }^{3}$ Pesquisa financiada com a Bolsa de Estágio Sênior da CAPES. 
professores, de CLIN (Classe d'Initiation pour les élèves non-francophones), adotarei esta denominação na sequência do texto.

\section{A partida}

Papai disse que nós íamos dormir e depois nós iríamos nos levantar, e depois ele me disse: "Ruben, nós vamos mudar de vida ». E eu subi no avião. Eu não sabia que nós iríamos vir para cá. Et voilá !"4 Ruben, de 6 anos, emigrante da República do Congo

«Mudar de vida ». Em sua pequena fala, Ruben define bem uma das principais questões que envolve os processos migratórios: a mudança, que se traduz, em muitos casos, pela ruptura com referências, famílias, idiomas, afetos. Ruben não sabia que a sua mudança de vida seria do Congo para a França. Et voilá! A partir de então, ele passará a ser classificado, de acordo com a definição adotada pelo Alto Conselho de Integração $(\mathrm{HCl})$ francês, como um "imigrante", ou seja, "pessoa nascida estrangeira, em país estrangeiro e ingressa na França nesta condição visando se estabelecer sobre o território francês de maneira duradoura." ${ }^{5}$

Ruben foi um dos pequenos imigrantes que conheci durante a pesquisa etnográfico-propositiva que realizei em escolas públicas da cidade de Paris, sobre performances narrativas contadas por crianças em situação de contato intercultural. Embora meu foco específico não fosse a imigração, o fato de estar trabalhando em Classes CLIN, que acolhem crianças recém-chegadas na França, rapidamente exigiu uma atenção para as relações ambíguas e não raro conflituosas entre o sentimento individual de ruptura e as políticas de integração implementadas pelo Estado francês. Considerando que a escola é a primeira e a mais importante dentre as instituições republicanas francesas com a qual as crianças têm contato (Cahuc et alii 2011: 80), é neste ambiente que o jovem imigrante, tão logo chegue ao país, vai encontrar acolhida e também vai se deparar com a diferença, com a alteridade. Refletindo sobre as relações identitárias em situação de diáspora, Stuart Hall (2003: 28) questiona:

Como podemos conceber ou imaginar a identidade, a diferença e o pertencimento, após a diáspora? Já que a 'identidade cultural' carrega consigo tantos traços de unidade essencial, unicidade primordial, indivisibilidade e mesmice, como devemos 'pensar' as identidades inscritas nas relações de poder, construídas pela diferença, e disjuntura?"

Minha hipótese é que, no caso das crianças imigrantes,

\footnotetext{
${ }^{4}$ No original : «Papa, il a dit qu'on va dormir et après on va (se) reveiller, et après il m'a dit: ' Ruben, on va changer de vie'. Et je suis monté à l'avion. Je savais pas qu'on allait venir ici. Et voilá !»

5 "Personne née étrangère à l'étranger et entrée en France en cette qualité en vue de s'établir sur le territoire français de façon durable. » Disponível em http://archives.hci.gouv.fr/-Mots-de-l-integration-.html (acesso em 06.10.2014) Tradução minha.
}

interlocutoras desta pesquisa, esses sentimentos ou "identidades" são organizados, traduzidos e mesmo inventados em performance. São suas as vozes em diáspora mencionadas no título, que procuraremos ouvir aqui.

\section{A chegada}

Tão logo chegue à França, toda criança tem o direito de ser matriculada na escola. Tanto os não-falantes de francês quanto aqueles que já tem noções básicas do idioma são encaminhados às CLIN. Atualmente existem 50 dessas Classes de Iniciação em escolas parisienses, contabilizando em média 850 alunos $^{6}$.

A ideia de ensinar a língua francesa a jovens imigrantes, a fim de "promover seu acolhimento e integração", conforme consta em diversos documentos oficiais do Ministério da Educação francês ${ }^{7}$, remonta pelo menos cinquenta anos, coincidindo com a independência de colônias francesas e com o afluxo de grandes contingentes de imigrantes ao país. Embora a circular que oficializa a implementação das CLIN nas escolas francesas date de $1970^{8}$, a primeira CLIN foi aberta em 1965 e em 1968 já se podiam contabilizar 39 Classes de Iniciação em funcionamento na França (Gautier, 2006). Esta circular prevê que todas as crianças recém-chegadas passem por um período de adaptação na CLIN, que poderá variar de alguns meses até um ano (ou mais, em casos específicos), dependendo das demandas de aprendizagem. O número de horas durante as quais a criança frequentará a CLIN também dependerá da avaliação feita pela equipe pedagógica, mas o mínimo previsto é de 12 hs semanais de estudo da língua francesa. A meta é integrá-la pouco a pouco na classe ordinária, correspondente, em geral, a sua faixa etária. Este processo de integração inicia pelas aulas de música, artes visuais e prática esportiva, e paulatinamente passa a contemplar as aulas de matemática, francês e ciências naturais e está pautado na ideia de que a integração parcial favoriza as trocas linguísticas com outros alunos francófonos, contribuindo para a aquisição da linguagem e da cultura - entenda-se, cultura escolar, com suas regras e normas, mas também cultura francesa em sentido amplo (Vasseur, 2003). Nesta estrutura, a língua francesa é considerada simultaneamente como objeto de estudo e como meio de acesso aos saberes locais (Carré e Sabrier, 2009). O boletim oficial de educação nacional $n^{\circ} 10$, de 25.04.2002, explicita esse aspecto:

\section{(...) si la maîtrise de la langue française dans ses usages}

\footnotetext{
${ }^{6}$ Informações fornecidas pelo CASNAV (Centre Académique pour la scolarisation des nouveaux arrivants et des enfants du voyage), em novembro de 2015. Disponível em: https://www.ac-paris.fr/portail/ upload/docs/application/pdf/2015-10/carte_upe2a_1er_degre_2015. pdf

${ }^{7}$ Ver Boletins Oficiais do Ministere de l'Education Nationale, $n^{\circ} 141$ de 02 de outubro de 2012 e 102, de 25 de abril de 2002, entre outros. Disponíveis em: http://www.education.gouv.fr/pid285/bulletin_ officiel.html

${ }^{8}$ Circular n IV-70-37 de 13 de janeiro de 1970.
} 
oraux et écrits est une priorité, l'apprentissage du vivre ensemble constitue une autre finalité essentielle de l'école. Ainsi, I'intégration en milieu ordinaire constitue non seulement un principe ou un objectif mais aussi la modalité principale de scolarisation.

Uma CLIN deve receber, no máximo, 15 alunos ao mesmo tempo, mas essa quantidade varia bastante, de acordo com o número de crianças que chegam (o que ocorre ao longo de todo o ano escolar) e daquelas que vão sendo integradas. Como o fluxo de alunos que matriculadas na CLIN é imprevisível e possui características muito distintas, a escolarização deste público exige uma organização pedagógica bastante maleável, bem como professores especialmente preparados para lidarem com estas especificidades ${ }^{9}$. A professora Noëlle Ebel, que acolheu minha pesquisa e se tornou importante parceira de trabalho, já atuava há mais de 10 anos na CLIN e conhecia profundamente a realidade destas classes, pois havia trabalhado em escolas de diferentes regiões (arrondissements) de Paris.

Percebi a diversidade e imprevisibilidade que caracterizam a CLIN assim que comecei minha pesquisa, em fevereiro de 2014, na École Keller, que está localizada no 11 ème arrondissement de Paris, um bairro conhecido por acolher trabalhadores imigrantes de diversos países. Na turma havia 13 crianças, das seguintes origens: 1 do Chade, 2 do Senegal, 3 da Guiné-Bissau, 2 do Marrocos, 1 da Romênia, 1 de Portugal, 1 da Colômbia, 1 de Bangladesh e 1 do Brasil. Durante os meses em que a pesquisa se desenvolveu, chegaram mais 2 alunos da República do Congo (dentre os quais Ruben), 2 da China e 1 dos Estados Unidos.

Já na CLIN de École Eugène Varlin (10 ème arrondissement), onde se desenvolveu a segunda fase da pesquisa, havia, em setembro de 2014, 6 alunos, 1 proveniente da Espanha, 1 da Mauritânia, 1 da Moldávia, 1 do Brasil, 1 da Gâmbia e 1 da Argélia. Posteriormente a classe recebeu mais quatro crianças, 2 do Senegal, 1 da Romênia e 1 da Espanha.

Como se pode perceber, cada CLIN se configura como uma pequena Babel. No entanto, ao contrário da cidade bíblica cujo castigo foi que seus habitantes passassem a falar diferentes línguas, nesta Babel escolar todos devem abandonar suas línguas de origem e dominar um mesmo idioma, o francês. Poderíamos nos perguntar: falar a mesma língua garante a comunicação? Se concordarmos com Mesmin (1995: 37) que a língua não é somente um conteúdo, é igualmente um continente que não se limita a um conjunto de palavras, mas reenvia à associação de ideias, como podemos pensar o aprendizado do francês em situações de origem cultural, étnica, religiosa e

\footnotetext{
${ }^{9}$ De acordo com o Bulletin Officiel [B.O.] n³9 du 28 octobre 2004, para lecionar nas CLIN o/a professor/a deve ter, preferencialmente, formação superior em Francês Língua Estrangeira (FLE) e ser aprovado no concurso específico para Francês Segunda Língua (FLS).
}

econômica tão distintas? O que as crianças da CLIN estão contando quando contam suas histórias em francês? Acredito que as narrativas orais ocupam um lugar especial neste contexto de interações comunicativas, pois possibilitam um acesso privilegiado às concepções, interpretações, sonhos e reflexões que as crianças têm a respeito de sua realidade. Como assinala Gilka Girardello (2007: 54,55):

(...) é ouvindo histórias (lidas e também contadas livremente, inspiradas na literatura ou na experiência vivida) e vendo ouvidas as suas próprias histórias que elas [as crianças] aprendem desde muito cedo a tecer narrativamente sua experiência, e ao fazê-lo vão se constituindo como sujeitos culturais.

Antes de conhecermos algumas das narrativas das crianças da CLIN, vejamos como se deu a pesquisa na prática. A primeira fase foi desenvolvida entre os meses de fevereiro e julho de 2014, na École Keller, e a segunda entre os meses de setembro de 2014 e janeiro de 2015, na École Eugéne Varlin. Propus à professora Noëlle uma pesquisa etnográfica-propositiva, na qual eu faria uma oficina com as crianças chamada "Petits narrateurs". Ela sugeriu que incluíssemos um subtítulo: "Échangeons nos histoires". Partimos da estrutura das sessões que eu havia realizado na escola brasileira e fomos adaptando às demandas específicas da CLIN. Neste processo, um material de apoio foi fundamental: o livro Grammaire de I'Imagination, do contista italiano Giani Rodari (1997). Nele o autor oferece uma série de procedimentos práticos para que as crianças criem suas próprias histórias. Para Rodari:

Les contes (écoutés ou inventés) ne représentent certes pas la panacée universelle dans l'éducation de l'enfant. Le libre usage de toutes les possibilités du langage ne constitue qu'une des directions dans lesquelles il peut s'épanouir. Mais tout se tient. L'imagination de l'enfant, stimulée pour inventer des mots, appliquera ses instruments à tous les domaines de l'expérience qui provoqueront son invention créative. Les contes servent à la mathématique comme la mathématique sert aux contes. Ils servent à la poésie, à la musique, à l'utopie, à l'engagement politique; bref, à l'homme tout entier, et pas seulement au rêveur. Ils servent justement parce qu'en apparence ils ne servent à rien (1997 : 183).

Nesta perspectiva de "livre uso das possibilidades da linguagem", planejamos 10 sessões de uma hora e meia por semana. A boa receptividade da oficina por parte das crianças e a riqueza de suas produções narrativas fizeram com que em poucas semanas esse planejamento fosse alterado, com a ampliação das sessões tanto em termos de duração quanto na quantidade de semanas. Durante a oficina eu atuava diretamente com as crianças e a professora permanecia como observadora. Nos demais momentos, como no recreio, a situação se invertia e eu 
me restringia a observar.

A oficina tinha a seguinte estrutura: iniciava com uma atividade lúdica (jogo, brincadeira) com todo o grupo, depois eu contava uma história e, numa relação de troca, o espaço era aberto para que os alunos pudessem contar suas próprias histórias. Procurei deixar bem claro que eles tinham total liberdade para contar o que desejassem. Tudo poderia ser considerado uma história: contos tradicionais de seus países de origem, histórias pessoais, contos de fadas europeus, fábulas, memórias de família, histórias inventadas, filmes... O ato de contar (e ouvir) histórias era tomado como uma práxis de partilha de experiências, que permitia a criação, ainda que limitada, de um mundo social viável (Jackson 2013) marcado, no caso, pelo espaço escolar. Parti, assim, da premissa de que as crianças, nas interações comunicativas com os pares e com os adultos, não estão não apenas refletindo, mas também constituindo modos de vida e de relacionamento (Sarmento 2002).

Depois de explicar quem eu era, minha origem e o que fazia ali, propus às crianças que fossem também "pesquisadoras". Dei a cada uma delas pequenos cadernos para que eles pudessem escrever, anotar, desenhar, copiar ou inventar as histórias que desejassem. Pautada na produção bibliográfica recente no campo dos estudos da infância, passei a considerar as crianças não apenas como interlocutoras, mas também como pesquisadoras e coprodutoras de dados e de reflexões (Begnami 2010; Alderson 2005).

Neste processo, as histórias iam surgindo por diferentes vias: escritas no caderninho, contadas oralmente, desenhadas, lembradas, improvisadas, sonhadas... No caso das histórias contadas oralmente, eu as transcrevia, imprimia e apresentava à criança autora, que fazia as revisões que achasse necessárias. Como "sujeitos autônomos" (Montandon; Longchamp 2007), as crianças não apenas elegiam o conteúdo e a forma de suas narrativas, como também operavam os equipamentos de registro em áudio e vídeo. Cada criança escolheu uma ou duas narrativas para fazerem parte do livro que seria entregue aos familiares no final do projeto e todas elas participaram do processo de confecção artesanal do livro, desenhando nas páginas impressas, auxiliando nas fotocópias e na encadernação, etc.

A opção por essa metodologia de trabalho, que chamei de etnográfico-propositiva, está pautada em uma atitude - acredito estética, ética e política - que prevê, por um lado, a coautoria das crianças na pesquisa, e por outro, a intervenção direta da pesquisadora no sentido de propor atividades lúdicas, questionamentos, formas de organizar o produto da pesquisa (no caso, um pequeno livro editado de forma artesanal por todo o grupo e um vídeo). Desta forma, as demandas e as transformações operadas em todos os envolvidos eram permanentemente avaliadas e, por sua vez, modificaram o próprio encaminhamento da pesquisa. A autonomia das crianças foi tão marcada que no final do processo na École Keller, por exemplo, após participarem do processo de confecção do livro, as crianças decidiram fazer uma versão reduzida para ser vendida por 2 euros na festa de final de ano da escola.

\section{Traduzindo/performando a nova vida}

Tendo em vista que toda interação comunicativa entre as crianças era marcada pelo exercício da tradução, percebi que traduzir, neste contexto, não se apresentava apenas como um processo de substituição de signos linguísticos, mas de compreensão, adaptação e, por que não, criação de significados. Como aponta Sarat Maharaj (apud Hall 2003: 41):

O significado não vem pronto, não é algo portátil que se pode "carregar através" do divisor. O tradutor é obrigado a construir o significado na língua original e depois imaginá-lo e modelá-lo uma segunda vez nos materiais da língua com a qual ele ou ela o está transmitindo. As lealdades do tradutor são assim divididas e partidas. Ele ou ela tem que ser leal à sintaxe, sensação e estrutura da língua-fonte e fiel àquelas da língua da tradução.

A tradução, ao mesmo tempo em que cria um obstáculo, potencializa a agência das crianças nas escolhas do que e como traduzir. A habilidade, a destreza, o sucesso na tradução estão ligados, se adotamos a perspectiva de Tim Ingold (2010), a uma "educação da atenção". Esta envolve um "conhecimento sensível" gerado por uma forma de aprendizagem ligada à sensibilização de todo o sistema perceptivo. Narrações de histórias, para Ingold, não são representações de algo, mas são "ações corporificadas no mundo" (2010: 23). As histórias surgem, portanto, no âmbito de relações intersubjetivas, que incluem a audiência.

Meu trabalho se desenvolveu, neste sentido, tentando identificar, registrar e analisar, não apenas os conteúdos das histórias contadas mas, sobretudo, as estratégias narrativas, gestuais e vocais utilizadas pelas crianças, ou seja, suas performances. Ao considerar o momento vivo da narração, em sua integralidade, estou enfatizando o contexto específico da performance, no qual a interação do performer com a audiência é fundamental. Meu embasamento teórico provém, assim, tanto do campo da etnografia da fala quando da antropologia da performance.

No âmbito do primeiro, o conceito de evento é fundamental. Jakobson (apud Briggs, 1996) atenta para a importância de uma forma particular de dialogismo que emerge nas narrativas, fazendo com que elas simultaneamente representem "eventos narrativos" - a situação discursiva da sua narração - e "eventos narrados" 
- as palavras e ações que eles relatam. Para Richard Bauman (1977), que também adora essa classificação, o evento designa um segmento limitado e culturalmente definido do fluxo de comportamento e da experiência, que constitui um contexto significativo para a ação. De acordo com seu parceiro Charles Briggs (1996: 22), esta manipulação formal da relação entre eventos narrados e eventos narrativos fornece uma importante base para a realização do comentário social através da forma narrativa.

Se para Dell Hymes (1975) a performance se define como um comportamento cultural através do qual uma pessoa assume a responsabilidade de contar, demonstrando competência comunicativa diante de uma audiência, para Bauman (1977) a performance realça a experiência e é sujeita à avaliação pelo modo como é realizada, pela habilidade e eficiência do performer. Embora estas definições tenham representado um avanço significativo na análise sobre "como" as narrativas orais são contadas, para Carlson (2010:27), Hymes e Bauman permanecem firmemente "contextuais", dando mais atenção à situação da performance do que às atividades específicas do performer.

Podemos avançar um pouco na proposta destes autores e admitir que a realidade social das crianças interlocutoras da pesquisa ao mesmo tempo em que é transmitida é também criada em performance. É aqui que entra a Antropologia da Performance: esta permite abordar as narrativas orais das crianças como fenômenos dinâmicos, ambíguos, multivocais, multisensoriais e efêmeros, cuja ênfase, em alguma medida, esteja posta em suas qualidades estéticas (Langdon 1996). Nesta perspectiva, o contexto narrativo pode ser contemplado de uma maneira mais holística e integral, sem, no entanto, desconsiderar que gestos, cores, sons, olhares, risadas, cochichos, hesitações, são também parte da execução performativa da fala (Raposo 2013: 14, 15).

Partindo da premissa da agência das crianças nos processos de performance e tradução, comecei a ouvir o que elas tinham para me contar. E diferentemente do que eu previa, meninos e meninas, negros ou brancos, do Senegal, do Marrocos, da Moldávia ou de Portugal, muçulmanos ou católicos, começaram narrando contos de fadas e histórias tradicionais francesas/europeias. Chapeuzinho Vermelho foi presença constante, assim como o Gato de Botas e Cinderela... As diferenças culturais e as experiências pessoais de cada criança pareciam, como na história de outra conhecida princesa, ter misteriosamente adormecido... Novamente Babel se mostrava ao contrário: a uniformização imposta da língua parecia indicar a homogeneização das narrativas. Mas nada como a duração da pesquisa etnográfica para romper o bloqueio das conclusões fáceis. A história que trago abaixo ajuda a vislumbrar outros caminhos de análise. Comecemos, finalmente, a ouvir as crianças:

\section{O desastre da floresta}

Contada oralmente em francês, em outubro de 2014, por Luiza, 9 anos (Brasil).

Era uma vez duas amigas que se chamavam Emma e a outra se chamava Luiza. Havia um menino que era o irmãozinho de Emma, Ibrahim, e o irmãozinho de Luiza, Mohamede. O pequeno grupo não tinha mãe nem pai porque eles estavam mortos. Um dia eles foram à floresta e viram uma fumaça. Ibrahim gritou:

- Socorro!

- Um homem veio e perguntou:

- o que está acontecendo?

- Fogo! Grita Mohamede.

- Rá Rá Rá!!! Fui eu que botei fogo! diz o homem. Saiam da minha frente!

E ele colocou fogo por tudo.

O homem tinha uma arma e explodiu a floresta inteira. Ibrahim pegou uma arma e atirou no homem, mas era muito tarde, a floresta estava incendiando.

Uma dama veio ver o incêndio e disse:

- Eu trabalho em um orfanato. Venham todos! Fim.

Nesta pequena narrativa, Luiza coloca a si própria e aos próprios colegas de classe em situação de orfandade. Emma é a amiga da mesma idade, de origem romena, que em sua trajetória migratória já havia passado algum tempo na Espanha. Ibrahim e Mohamede (usar nomes fictícios) são os pequenos gêmeos de 6 anos, recémchegados do Senegal, "adotados" pelas meninas. Nos enganaríamos se pretendêssemos entender que a realidade do grupo é representada na narrativa. Não há literalidade na "tradução" da realidade nem nas traduções entre idiomas. Interessa-nos perceber a complexidade de sua performance, pois enquanto o evento narrado revela uma situação de orfandade, de violência e, na conclusão, de acolhimento das crianças, o evento narrativo demonstra a habilidade da narradora ao servir-se de elementos característicos de performances orais, como os enquadramentos de inícios ("Era uma vez" e "Fim"), a fala reportada de alguns personagens ("Socorro!"), e uso de entonações vocais e gestuais específicos, entre outros.

Luiza, no entanto, já estava completando um ano na CLIN e dominava perfeitamente o francês. Observei que, na medida em que as crianças iam dominando o idioma, começavam a se sentir mais autônomas para criarem suas próprias histórias, frequentemente combinando, em diferentes medidas, fatos reais ou relativos ao contexto atual (como a menção aos colegas), com elementos ficcionais $^{10}$.

\footnotetext{
${ }^{10}$ Importante perceber que foi uma opção das crianças, profundamente respeitada por mim e pela professora, não contarem de forma realista suas trajetórias de migração ou suas vidas no país de origem.
} 
Veremos agora, de forma mais detalhada, acompanhando durante quatro meses Methelá, uma menina de 6 anos recém-chegada de Bangladesh, como o processo de aprendizagem do idioma foi se configurando no domínio da performance narrativa.

Quando comecei a pesquisa na École Keller, Methelá havia chegado há pouco tempo a Paris e ainda se comunicava com muita dificuldade em francês, falando apenas palavras soltas, sem formar frases completas. No entanto, ela manifestava fortemente o desejo de contar suas histórias. Abaixo apresento a sequência de narrativas contadas pela pequena contadora, registradas por mim e por Noelle em diferentes suportes.

Primeira narrativa de Methélá, contada oralmente no dia 14 de março de 2014:

\section{Cinderela}

A mamãe de Cinderela... Ela está morta, a morte.

Ela fez «Qua Qua»

A mamãe, ela disse : « Cinderela não está aqui. »

Ela tinha uma pequena bonequinha. ${ }^{11}$

Como se pode perceber, Methélá parte de um conto de fadas e esboça suas primeiras tentativas de contar uma história em francês, combinando elementos da cultura local (Cinderela) com formas de expressão que caracterização suas performances posteriores, como a fala de personagens e os sons onomatopaicos ("Qua Quá"). Embora ainda falando com frases soltas em francês, em sua performance ela já demonstra especial habilidade para representar as vozes dos personagens ("Cinderela não está aqui"). Esse dispositivo, conhecido por pesquisadores do campo da arte verbal como a fala repostada (reported speech), é um dos principais dispositivos utilizados pelos contadores para conectarem os eventos narrados (o que é contado) aos eventos narrativos (o contexto de narração) (Bauman e Briggs, 1990).

Segunda narrativa de Methélá, contada a partir dos desenhos que havia feito em sua caderneta, no dia 25 de março:

Era uma vez... Ele dança...

Eu amo pizza, salada, queijo. Eu amo leite. Minha mamãe me dá leite. Eu durmo. Depois eu venho aqui, eu vou à recreação. Mamãe veio. É como uma pequena história: Qua Qua Qua!

Mamãe lê histórias dos livros, histórias de rir. É bom. Seus cabelos são assim. Essa é minha foto. Mamãe me disse: "Você é tão bela, Methélá!"

Essa é minha boneca. Essa é minha casa. Essa é a

\footnotetext{
${ }^{11}$ Cendrillon

Le mamam de Cendrillon... Elle est mort, la mort.

Elle a fait «Qua Qua !»

La mamam, elle a dit : « Cendrillon elle n’est pas lá».

Elle avait une petite poupée.
}

escola. Esse é o jogo. Essa é a cantina, onde eu como. É bom! $!^{12}$

É possível perceber que esta narrativa é composta a partir de aspectos da vida cotidiana de Methélá, no entanto, a fórmula de início ("Era uma vez"), ao reestabelecer o vínculo com os contos de fadas, permite um "enquadramento"13 da narrativa numa estrutura que é utilizada convencionalmente na narração de histórias em língua francesa. O reported speech e os sons onomatopaicos são recursos novamente utilizados pela pequena narradora.

Terceira narrativa de Methélá, escrita pela professora a partir do que ela lhe contava, no dia 10 de abril:

\section{Eu e mamãe}

Minha mamãe me dá para comer leite com chocolate. As duas meninas vem de Bangladesh e uma menina vem da França.

La menininha da França cresce um pouco.

Sua mãe lhe diz : «É preciso ir à escola. »

Então, ela vai à escola.

Ela vai para a aula junto com a Chapeuzinho Vermelho e a segunda menina. Nós trabalhamos bem na turma. Durante esse tempo, mamãe descansa. (... $)^{14}$

Aqui novamente acompanhamos a narrativa de uma história pessoal (conforme já está indicado no título da história), que é melhor compreendida se conhecemos o contexto de imigração de Methélá: ela e a mãe vêm de Bangladesh, o pai havia falecido e a mãe chega grávida à França. A irmãzinha de Methélá já nasce no novo país. No entanto, os contos de fadas se fazem novamente presentes: desta vez Chapeuzinho Vermelho vai para a aula com a menina e a importância da integração das crianças à realidade local é reforçada na fala reportada da mãe: "Tem de ir à escola". A inclusão de elementos

\footnotetext{
12 II était une fois... II danse...

J'aime la pizza, de salade, de fromage. J'aime du lait. Ma mamam m'a donné du lait. Je m'endormis. Après je viens ici, je vais a la recreation. Mamam ella a venu. C'est comme une petite histoire : qua qua qua!

Mamam lit les histoires des livres, les histoires de rire. C'est bon. Ses cheveux sont comme ça. Ça c'est ma photo. Mamam m'a dit : « Tu es tellement belle, Methella. »

Ça ce ma poupée. Ça ce la maison. Ça ce l'école. Ça ce le jeu. Ça le la cantine, où je mange. C'est bon !

13 Esses dispositivos, chamados de "keys", por Bauman (1977), "frames", por Goffman (1983) são internos às próprias performances narrativas e são utilizados para sinalizar que uma história começará a ser contada.

${ }^{14}$ Moi et maman

Ma mamam me donne à manger du lait au chocolat.

Les deux filles arrivent du Bangladesh et une fille vient de France.

La petite fille de France grandit un peu.

Sa mamam lui dit : " Il faut aller à l'école. »

Alors, elle va a l'école.

Elle va en classe ensemble, avec le Petite Chaperon Rouge et la deuxième fille. On travaille bien en classe.

Pendant ce temps, mamam se repose. (...)
} 
dos contos de fadas em outras formas narrativas pode ser lida ainda como parte do processo que Hall chama de transculturação, através da qual "grupos subordinados ou marginais selecionam e inventam a partir dos materiais a eles transmitidos pela cultura metropolitana dominante" (Hall 2003: 31).

Quarta narrativa de Methélá, contada oralmente no dia 14 de maio, escrita no caderninho pela professora e revisada por ambas no dia 22 de maio.

\section{O menino e a serpente}

Era uma vez um menino que se chamava Sator e que pescava peixes no mar.

Uma noite, enquanto ele dormia, uma serpente entrou na sua casa.

A serpente estava sobre sua barriga, depois sobre seu rosto. O bebê que estava perto dele começou a gritar. Quanto Sator se acorda ele vê a cabeça da serpente, a boca aberta e a língua saindo bem diante dele.

Ele pega a serpente pelo pescoço e a estrangula.

O bebezinho continuava a chorar. Depois ele se acalmou, ele chorava bem suavemente e enfim ele sorri.

Não havia mais perigo. ${ }^{15}$

Como se pode perceber, houve um trabalho minucioso da professora no sentido de estruturar a narrativa de Methélá de forma coerente, atribuindo-Ihe início, meio e fim. Referências ao país de origem da menina parecem vir à tona, através da menção ao pescador, cujo nome, Sator, é também o de uma cidade de Bangladesh.

A mesma narrativa foi contada ainda outra vez pela menina, em junho, quando fizemos um registro em vídeo de uma narrativa de cada criança da turma ${ }^{16}$. Naquele momento foi possivel perceber que os eventos narrados e a descrição dos personagens estavam mais detalhados e a performance de Methélá mais elaborada, pois ela representava os diferentes personagens (o bebê e Sator) com seus gestos e expressões específicos. Ao invés de "era uma vez" ("il était une fois"), Methélá usa a fórmula de início de um pequeno poema, aprendido na escola, que passa a servir como referência de abertura enquadre) de todas as suas narrativas ("il était une fois un marchand de

\footnotetext{
${ }^{15}$ Le Garçon et le Serpent

Il était un fois un garçon qui s'appelait Sator et qui pêchait des poissons dans la mer.

Une nuit, pendant qu-il dormait, un serpent est entré dans sa maison. Le serpent s'est sur son ventre, puis sur son visage. Le bebé qui était près de lui se mit a crier.

Quand Sator se reveille il vit la tête du serpent, la bouche ouverte et la langue sortie juste devant lui.

Il saisit le serpent à la gorge et l'étrangla.

Le petit bébe continuait a pleureur. Puis il s'est calmé, il pleurait tout doucement et enfin il sourit.

II n'y avait plus de danger.

${ }^{16}$ Este vídeo foi anexado ao livro que foi distribuído aos familiares no final do ano letivo (julho de 2014).
}

foie"17). Ela explora fortemente os sons onomatopaicos, pois percebe que sua audiência reage com risos. Durante a performance ela muda o nome do personagem Sator pelo de seu colega de classe, Mahmoud, que a assistia durante a gravação do vídeo. O evento narrativo (a performance), assim, mostra-se mais importante que o evento narrado (o conteúdo), o que corrobora com a perspectiva de Richard Bauman (2004), de que a vida social se organiza através de atos de linguagem. Estes, embora ancorados no contexto, também o transcendem, porque estão ligados de maneira interdiscursiva a outras situações e outras enunciações.

Desta forma, o processo de aprendizagem de Methélá, assim como o de muitas outras crianças imigrantes na mesma situação, não pode ser pensado apenas em relação ao nível de aquisição da língua francesa e de capacidade de tradução, mas, num sentido mais amplo, em relação a todos os "conhecimentos sensíveis" (Ingold 2010) adquiridos sobre distintos âmbitos, como as regras da escola, os tipos de estrutura narrativa, a atenção do público ouvinte... Como diz Francols (2009: s/p):

En situation de contact avec une langue étrangère, on a souvent l'impression que notre interlocuteur ne comprend pas mais en réalité, il comprend beaucoup plus qu'il ne produit, à l'aide du contexte, des gestes, des mimiques, des supports (images par exemple) que l'on a sous la main.

Embora a maior parte dos trabalhos relativos ao desenvolvimento da linguagem oral tomem por objeto as competências linguísticas mais do que as competências pragmáticas e discursivas. (Coletta 1998), as estratégias verbais, vocais e gestuais utilizadas pelas crianças imigrantes são fundamentais no processo de "tradução cultural" operado cotidianamente por elas.

Como vimos, através do exercício de criação e troca de histórias as crianças imigrantes encontram meios de expressar a nova realidade. Talvez devêssemos prestar mais atenção à essa "forma cultural diaspórica" (Hall 2003) que pode estar surgindo no encontro destas crianças. Uma dama gentil pode aparecer para abrigar órfãos que estão fugindo de um incêndio na floresta e Chapeuzinho Vermelho pode ir de mãos dadas com Methélá para a escola. "Mudar de vida", portanto, pode também mudar suas histórias.

Brasília/DF - Brasil, 15 de julho de 2016.

\section{Referências bibliográficas}

Alderson, P. (2005). As crianças como pesquisadoras: os efeitos dos direitos de participação sobre a metodologia de pesquisa. Educação e Sociedade. Campinas, v. 26, n. 91, p. 419-442.

\footnotetext{
17 Importante perceber que "fois" e "foie", embora com grafias distintas, são pronunciadas da mesma maneira.
} 
Bauman, R. (1977). Verbal Art as Performance. Rowley, Mass: Newbury House Publishers, 1977.

Bauman, R.(2004). A World of Others' Words. CrossCultural Perspectives on Intertextuality. Malden-Oxford, Blackwell Publishing.

Bauman, R.; Briggs, C. (1990) Poetics and Performance as Critical Perspectives on Language and Social Life. Annual Review of Anthropology. Palo Alto, Annual Reviews, v. 19 , p. 59-88.

Briggs, C. (1996). Introduction. In: BRIGGS, Charles (ed.) Disorderly Discourse - narrative, conflict and inequality. New York/Oxford, Oxford University Press.

Begnami, P. S. (2010). Crianças: os sujeitos das pesquisas antropológicas. Revista UNAR, Araras (SP), v. 4, n. 1, p. 2-12.

CASNAV. Les élèves nouvellement arrivés en France sans maîtrise suffisante de la langue française ou des apprentissages. Enquête statistique Premier degré Année scolaire 2009-2010. Disponível em: http://18b-gouttedor. scola.ac-paris.fr/IMG/pdf/statistiques_CLIN_09-_10.pdf Acesso em 06.10.2014

Coletta, J-M. (1998) Les conduites narratives chez I'enfant: une approche étho-linguistique et développementale. 6ème Congrès de I'International Pragmatics Association, Reims, juillet 1998.

Francols, N. Avec un ENAF en classe ordinaire. Cahiers Pédagogiques. $N^{\circ} 473$. Dossiê Enfants d'ailleurs, élèves en France. Disponível em: http://www.cahiers-pedagogiques. com/Avec-un-Enaf-en-classe-ordinaire

Gautier, M. (2005/2006) L'éclectisme de la classe d'initiation (CL.IN.) Mémoire pour le Concours de recrutement: Professeur des écoles. IUFM de Bourgogne.

Girardello, G. (2007). Voz, presença e imaginação: a narração de histórias e as crianças pequenas. In: FRITZEN, Celdon; CABRAL, Gladir S. (orgs.) Infância: imaginação e educação em debate. Campinas/SP: Papirus, 2007. p. 39-58.

Hall, S. (2003). Da Diáspora - identidades e mediações culturais. Belo Horizonte: Ed. da UFMG.

Hartamann, L. (2015). Equilibristas, viajantes, princesas e poetas: performances orais e escritas de crianças narradoras. Boitatá - Revista do GT de Literatura Oral e Popular da ANPOLL. UEL, Londrina, n. 20, p. 48-67.

Hymes, D. (1975). Breakthrough into Performance. In: BEN-AMOS, Dan; GOLDSTEIN, Kenneth S. (orgs.) Folklore - Performance and Communication. Paris: Mouton.

Ingold, T. (2001). From the transmission of representations to the education of attention. In: H. Whitehouse (ed.), The Debated Mind: evolutionary psychology versus ethnography. Oxford: Berg, 2001, p. 113-153.

Langdon, E.r J. (1996). Performance e Preocupações PósModernas em Antropologia. Antropologia em Primeira Mão. Florianópolis, PPGAS/UFSC. N. 11, 1996.

Mesmin, C. et alii. (1995). Psychothérapie des enfants de migrants. Paris : La Pensée Sauvage, 1995.

Montandon, C.; Longchamp, P. (2007). Você disse autonomia? Uma breve percepção da experiência das crianças. Perspectiva. Florianópolis, v. 25, n. 1, p. 105126.

Raposo, P. (2013). No Performance's Land? Interrogações contemporâneas para uma teoria da performance. In: DAWSEY, J.; RAPOSO, P.; FRADIQUE, T.; CARDOSO, V, Z. (orgs.). A Terra do Não Lugar Diálogos entre Antropologia e Performance. Florianópolis, Ed. da UFSC.

Rodari, G. (1997). Grammaire de L'Immagination. Paris: Rue du Monde.

Sarmento, M.J. (2003). Imaginário e culturas da infância. Cadernos de Educação, Pelotas, v. 12, n. 21, 2003, p. 51-69.

Skliar, C. (2003). A educação e a pergunta pelos Outros: diferença, alteridade, diversidade e os outros "outros". Ponto de Vista, Florianópolis, n.05, 2003, p. 37-49.

Vasseur, M.T. (2003). En CLIN, I'apprentissage du français passe par la socialisation en français. Linx, 49, 2003, p. 125-140. 